\title{
CROSS-DISCIPLINARY COLLABORATIVE ENTREPRENEURIAL EDUCATION: ZONE LEARNING AND ARCHITECTURE
}

\author{
C. Ripley \\ Department of Architectural Science \\ Ryerson University \\ cripley@ryerson.ca
}

\begin{abstract}
While we are clearly in the early stages, Zone Learning presents a significant potential shift in architectural education. This paper presents the impetus behind the DFZ, addressing its relationship to a professional program in architecture, and identifying gaps in the professional program that the DFZ assists in resolving. The paper also discusses the organization of the DFZ (and of Zone Learning in general) from institutional, spatial, resource and pedagogic points of view. A few of the many projects carried out within the DFZ are presented and the changing relationships between architecture and the rest of the University, on the one hand, and the Profession, on the other, considered. Finally, the paper speculates on future developments within the DFZ and how those might impact, in turn, the professional program in architecture.
\end{abstract}

Keywords: Entrepreneurialism; Zone learning; Incubators 


\section{ZONE LEARNING: AN INNOVATIVE PARADIGM}

In October 2013, The Department of Architectural Science at Ryerson University, in joint venture with the School of Interior Design, launched the Design Fabrication Zone (DFZ), a new initiative in collaborative, cross-disciplinary entrepreneurial education for the design disciplines that bridges the gap between academic learning and professional practice.

Zone Learning - of which the Design Fabrication Zone is an application to the design disciplines - was inaugurated at Ryerson, a large University with about 35,000 students located in downtown Toronto, with the opening of the Digital Media Zone (DMZ) in 2010. Unlike the bottom-up development that is more typical of Ryerson, the DMZ was a direct initiative of the President's office, largely in response to a small but perceptible student need. In Zone Learning, a potential participant - who may be a student, alumnus, faculty member, or anyone else comes to the Zone with an idea to develop - for a product, service, or business. Zone participants are provided with space to work as well as mentorship and other resources they may need in order to develop their ideas, including in areas such as marketing, business development, accounting, and human resources. The Zone experience is supplemented with workshops, discussions, roundtables and so on - but the most important resource is the multi-disciplinary community of zone members providing peer support.

Since 2010, Zone Learning has expanded rapidly at Ryerson, even as we come to grips with what it is and how it operates in conjunction with traditional education. The DMZ has garnered considerable international interest; it is now the top-ranked university business incubator in Canada, and the fifth-ranked in the world (UBI Index, 2015). There are now six Zones at the University, including the Design Fabrication Zone, or DFZ (Ryerson University, 2014). The DFZ is intended for participants who need the tools and processes of digital fabrication in order to carry out their ideas and projects, which vary from product design, to competition entries, to full-scale installation work - and conceivably even the design (and construction) of small buildings. Zones are a free-flowing ground for interdisciplinary innovation across the University, affecting all areas of society; collaboration across Zones is encouraged. Indeed, Zones operate in principle outside of normal academic structures. Connections to academic programs are either minimal or even completely absent, and students do not gain program credit for their work in the Zones - indeed, again in principle, Zone participants do not need to be students at all. Zone Learning is in many ways an inversion of traditional post-secondary classroom (or even studio) education, as projects, process, schedule, parameters, outcomes and even evaluation are selfdetermined by learners rather than delivered by instructors. Learning is put firmly into the responsibility of the learners, motivating and energizing them. In short, Zone Learning is a fascinating experiment into the nature of post-secondary education, and one with significant lessons for those of us engaged in the development of traditional academic programs.

The question of how to develop administrative structures and processes for Zones in the context of an already well-developed University administration has been a matter of considerable discussion and design activity over the past two years. In the first years of its operation, the Digital Media Zone operated on a very simple principle: applicants would need to be accepted on the basis of a strong business plan, and would be provided with workspace in the DMZ at a below market-rate rental cost which would be waived for an initial period. In other 
words, there was no formal connection at the outset to the University structures. By 2012, however, it had become clear that in order to achieve stable long-term funding of the DMZ and of the new Zones that were emerging, a clearer and more direct connection to traditional University administrative procedures would be needed. We would need some way, for example, of tracking enrolment - even if only for the purposes of reporting to government, as we are a publicly funded university. At the same time, students working in the Zones would benefit from some official record of their activities on their University transcripts. Making this situation more complex, each of the Zones that had already come into existing by 2012 had its own mechanisms for membership and its own relationships to curricula on the one hand and to faculty research on the other, while other new curricular or quasi-curricular mechanisms were in development with the aim of fostering entrepreneurialism. All of these would need to be accommodated in a registrarial system that could legitimize the Zones from a ministerial point of view, without disrupting their freedom and ability to operate as a new and innovative educational paradigm.

Currently, we have developed a very simple system whereby Zone members are required to enroll in a one-credit course in Zone Learning . Ryerson program students do not pay tuition for this course, which is not available as a credit in their programs; however, on completion of a number of semesters of Zone Learning they receive a special designation on their transcripts.

\subsection{The Design Fabrication Zone}

During the first two years of its operation, the DFZ has been funded as a pilot project from the Provost's office, with additional support from the Department of Architectural Science and the School of Interior Design. The DFZ has two codirectors, one from each academic unit involved, who report to Ryerson's Director of Zone Learning who in turn reports to the Provost. This structure is important in that it places the DFZ - and all other Zones - outside of the direct authority of the academic units and removed from issues of curriculum. So, for example, although Filiz Klassen from Interior Design and I developed the proposal for the DFZ and, over the course of almost a year, worked hard to develop support for it, as Chair of the Department of Architectural Science I did not participate as a co-director, although remaining, as Chair, on the steering committee.

The DFZ functions primarily out of a workspace developed for it near the Ryerson campus, which functions as "clean lab" space, shared with some research space used by faculty involved in advanced manufacturing research. Zone members have access to the digital fabrication facilities in the School of Interior Design and the Department of Architectural Science, although in the longer term the Zone will develop its own fabrication space. In addition to the co-directors, the DFZ has several technical staff members who assist with the use of the equipment, provide design expertise and feedback and offer workshops and tutorials, with other faculty members brought in to offer specialized sessions in areas of their own expertise. In addition to the fabrication facilities and the Zone headquarters, DFZ members have access to the Zone Learning Centre, a drop-in collaborative workspace that we created in the fall of 2014 in the Architecture Building. 
As I alluded to above, all of these arrangements for space and facilities have been developed in an opportunistic fashion, taking advantage of what we might have available to us at the moment in order to be able to begin to operate the Zone, and we understand that these arrangements are both less than ideal and temporary. One example I would like to unpack a bit is access to the digital fabrication facilities in the Architecture Building, which are under my purview as Chair of the Department of Architectural Science. These facilities have been under considerable pressure for a number of years, as the demand for their use has grown exponentially with students producing more and more installation work in addition to using the equipment for more traditional architectural modelmaking. By 2012, our shop technicians were clearly overworked as a result, and although they did not complain, it was clear to me that the situation needed to be resolved. Part of my strategy, as Chair, was to recognize that much of this work could fall under the aegis of the DFZ, and we could use the DFZ as an opportunity to increase support for the shop.

In order to increase access to fabrication equipment, we recognized that one could either increase the amount of equipment - more laser cutters and milling machines - or increase the hours per day during which it could be used (and I should mention here that Ryerson operates in a union environment). More equipment requires capital for purchasing the machines, which can be found, but more importantly requires space for their installation and assorted other infrastructure. Extending the hours of shop access requires additional staffing as we are required to have a technician in the shop overseeing the work at all times. As a result, neither of these solutions is easy or inexpensive. By working directly with the Provost's office and with the Director of Zone Learning, we were able to attack the problem on both sides. We were successful in obtaining funding for a significant renovation of the fabrication shop to facilitate the work of the Zone (this renovation is still ongoing). Meanwhile, technicians that are part of the Zone operation are able to keep the shop open into the evening hours, to the benefit of both Zone members and our program students. Neither of these initiatives is fully operational at the time of writing, but once both are I anticipate that the pressure on our fabrication shop and its staff will decrease to a manageable level. In other words, although the Zone sits outside of academic programs, by seeking out synergetic relationships between Zones and programs it is possible to benefit both.

Despite the necessary ad-hoc nature of the structure and facilities of the DFZ during its initial year and a half of operation, the Zone has already demonstrated significant success and impact. During its first year, the DFZ attracted some 150 members, all, during this trial period, program students from a number of different units in the University, and produced some thirty entrepreneurial projects (FEAS, 2014). These projects ranged from product design to large-scale installations for major local art and design events such as Scotiabank Nuit Blanche Toronto (www.scotiabanknuitblanche.ca) and Come Up to My Room (www.comeuptomyroom.com), and included collaborations with both business and arts organizations in the city. On the whole, the first indications are that the DFZ is already, and will continue to be a success - but what are the rationales for and benefits of this novel educational structure in the context of architectural education? 


\section{ARCHITECTURAL EDUCATION AND ZONE LEARNING: HOW CAN WE TEACH PRACTICE?}

There has been much discussion in recent years about changing conditions for and structure of architectural practice. On the one hand, changing economic conditions, driven in part by the increasing corporate structure of architectural firms, coupled with the ease of global communications and of global practice, has resulted in much larger firms than were common one or two decades ago. While the dominant form as late as the 1990s was the local, comprehensive mid-size firm of perhaps fifty to one hundred employees, able to take on projects of many different types, large multi-national firms with multiple offices, thousands of employees and clear areas of specialization are now the major players. As RIBA has noted in a recent report, the mid-size firm is likely to vanish in the coming decades, leaving the very large firms on the one hand, and small, boutique practices on the other (Robinson, Jamieson, Worthington, Cole 2010). Meanwhile, changing business practices developed in response to issues of risk management on the parts of increasingly large development and construction companies, exacerbated by the disruptive effects of production technologies such as BIM, have radically altered - and will likely continue to alter - the workings of architectural firms, requiring a far more sophisticated business strategy than would have been needed in the past and changing all of the contractual relationships among parties in the construction industry. To make matters worse, the fundamental tools of both design and construction are in the midst of a radical overhaul, with the development of BIM, parametric design, performance simulation and advanced manufacturing technologies poised to once again change the basic conditions for the construction industry, and hence for architecture (Ripley, 2012).

In this situation, it is clear that graduates from today's professional programs in architecture will likely have a very different career path than those of architects of my generation - although it is not entirely clear what those career paths will look like. We can speculate, though - with reasonable confidence - that deepened expertise in three areas will allow our current graduates to navigate this uncertain territory: a deeper understanding of business practices, including contemporary and advanced business practices, coupled with developed entrepreneurial skills; a more intimate and fluid relationship to emerging technologies of design and construction as means of production; and a more developed ability to collaborate across disciplines, building bridges between silos, opening both new design possibilities and new areas of practice. The Design Fabrication Zone has been developed in order to address these three areas of concern.

\section{$2.1 \quad$ Entrepreneurial learning}

While the career path for the majority of graduates of professional programs in architecture will continue to include a lengthy period of continued learning within large architectural practices, we have identified a small component of students whose entrepreneurial nature will direct them to an alternative career, including the formation of their own businesses immediately upon - or even prior to graduation. Although I have no data to support this, we estimate that percentage to be between five and ten percent of graduating students. The DFZ has been designed to provide mentorship and just-in-time training to allow these students to develop the skills and instincts needed to run a successful business, through a 
combination of mentorship, targeted seminars and workshops, and - perhaps most importantly - a basic structure based in experiential learning.

The question of how to teach issues of practice within professional programs in architecture is a thorny one. While schools, by and larger, do an excellent job of teaching design - including the cultural and technological aspects of the design of buildings - they are not so strong in teaching students how to operate as an architect within a business climate. In Canada, for example, most programs will offer no more than a single one-credit course in business practices, while the Canadian Architectural Certification Board's Student Performance Criteria - by which programs are evaluated - contains only one Criteria (of the 37 in total) related to architecture as a business. A recent position paper by the Ontario Association of Architects suggested that

Practitioners are looking for graduates entering the workforce who are able to produce; are more entrepreneurial with a better understanding of the business of practice, construction, and development; and who are risk managers. (OAA, 2014, 16)

In developing the DFZ, we have taken the position that at the root of the difficulty with business training in schools of architecture is a double problem of abstraction: in the absence of a real business, concepts around marketing, finance, management and so on can only be discussed in an abstract fashion, while the very idea of business education can itself seem abstract and unnecessary to many students who are focused to an extreme on developing their design voices. By connecting entrepreneurial and business skills development to real projects, in which the students have a real stake, the DFZ aims to sidestep this double bind. We have removed abstraction from the scenario.

Although at present this mode of learning is available to only a small group of self-motivated learners, it is my hope that the lessons and techniques can be extended into new thinking about business skills development for the entire population of architecture students.

\subsection{The emerging technologies gap}

New technologies of architectural production, ranging from digital design methods to advanced manufacturing technologies, have become indispensible tools for today's cohort of students. This is especially true among students who are especially ambitious and motivated. It is a reasonable statement that for the small group of especially entrepreneurial students identified in the previous section, it would be inconceivable to formulate a business idea without regular if not constant access to equipment such as laser cutters, 3d-printers, milling machines, robotic arms and the like - and whatever new equipment bursts onto the scene in the coming few years.

Meanwhile, the increased pace of technological change in terms of architectural production has also created a conundrum for young practitioners, a few years out of their formal education, but whose technical skills are already lagging behind those of more recent graduates. Continued rapid technological development will lead to a permanent situation in which young architects at a crucial stage in their careers need to re-acquaint themselves with new tools - whether they intend to 
start their own firms or not. If they do intend to set up shop as an independent practice, then the increased capital needed to have access to advanced technologies is an added obstruction in the road. We are starting to see dynamic and exciting young practices, such as Toronto's Partisans, investing heavily in their own digital fabrication shops - but of course, not all young practices have the financial means to make this investment.

The DFZ looks to bridge this particular gap by providing incubation to new design businesses in the context of access to a well-equipped fabrication shop, complete with instruction and guidance, offered - like the entrepreneurial aspects of the DFZ - in a just-in-time model divorced from abstraction. In the coming years we intend to augment this with new for-credit programs linked to the DFZ but aimed at mid-career professionals. However, the goals of the DFZ go beyond just teaching people how to use robotic arms: it is our argument that a seamless integration between business education and advanced manufacturing is critical in order to operate in a $21^{\text {st }}$-century production paradigm. How, for example, could a small business owner estimate a price or a schedule without a deep understanding of the techniques of production? What are the cost and time implications of 3d-printing? Tomorrow's design entrepreneurs will need to understand advanced manufacturing processes and business processes as two aspects of a single, interconnected system.

\subsection{Connecting silos}

There has been much talk in architectural education of en expansion of architecture beyond its traditional disciplinary boundaries - as we can see for example in the title of this year's ACSA Annual Meeting, The Expanding Periphery and the Migrating Centre. There is a belief, at least in the academy, that architects are spending more time engaged in issues that would have been at best peripheral a generation ago, ranging from urban and landscape design to product design, manufacturing design, and policy discussion. It is understood that the basic competencies of architectural design provide a strong methodology that can be applied in many fields - witness the development of design thinking in the business community in recent years. Indeed, due to the technological changes referenced above, it is likely that this kind of work outside of the realm of building design is likely to be more prevalent among out graduates in the coming decades.

Of course, the question of inter-disciplinary collaboration in architecture is not just a question for the academics. Practitioners will be able to show quite clearly the extent to which architectural design has increasingly become a group activity, whether one is referencing the increasing need to involve the public as well as other stakeholders, or the increasingly numerous specialized consultants involved in a project. The architect - probably always, but maybe more today and in the future - must be an expert in organizing and managing collaborative processes.

However, one of the difficulties inherent in modeling collaboration in architecture schools is that the collaborators - generally architecture students - have more or less the same training, knowledge and abilities. It is remarkably difficult to set up interdisciplinary collaborations within the school. Although such collaborations do happen, they are difficult to organize and most often short-lived. For example, an attempt to organize a joint architecture/urban planning/interior design studio in 
our own school was thwarted by administrative problems - namely, that we could not manage to organize a common time slot in the schedule for all three groups to meet. But this is precisely the type of collaborative experience that students need - and not just with other building-related disciplines, but also with engineers, artists, scientists, and social groups.

The DFZ looks to address this problem by bringing together groups with different areas of expertise into the same structure and simply allowing collaborative projects to take form. Students learn first-hand of the challenges - and the power - of interdisciplinary collaboration. Our model for this is connecting silos allowing, indeed requiring, disciplinary expertise, but then providing mechanisms by which those areas of expertise can be brought together profitably. In order to make this work, membership in the DFZ is not limited to students in architecture or interior design; any student, or for that matter a non-student, who has an idea or project that requires digital fabrication to be fully realized is welcome to join the Zone. In addition, we have developed the Zone Learning Centre, a collaborative workspace located in the architecture building, adjacent to the fabrication shop, but open to all Zones on campus - including the Fashion Zone and the Social Ventures Zone; this Centre has been referred to by one of my colleagues as the "barnyard", the place where the work in the silos is brought out and interdisciplinary play takes place. We have already begun to see the fruits of this, as serendipitous collaborations across the Zones are starting to take place.

Finally, the DFZ is also intended to function as a mechanism for collaboration between academia and practice - although this aspect remains latent. The development of businesses as a result of Zone activity is one of the prime arguments for the Zones: they contribute directly to economic development. Indeed, all the Zones sit somewhere between the academy and industry, with aspects that move back and forth along a spectrum between academic exercises and business activity. The DFZ is no different. For example, there is no prohibition from DFZ groups taking on projects for which there is a real client. One sign of success for the DFZ would be the rapid development of viable design practices, able to leave the Zone and operate on their own. Similarly, the development of research clusters within the Zone, collaborating with students and members of other zones, on the one side, and architectural practices and clients, on the other, could only be seen as a positive development. Such research practices could blur the distinctions between research and practice, as well as bringing the rigour of real practice into the academic setting.

\section{MOVING FORWARD}

As the previous section of this paper makes clear, the potential value of the DFZ and other entities like it goes far beyond what we have seen in the first two years of operation. We have a number of proposals in place or in development that will allow the DFZ to be more successful in its impacts on architectural education in general. In principle, there are three areas of development: establishing stable funding and administrative systems; initiating additional curricular and cocurricular components to enable and intensify the cross-collaborative possibilities discussed above; and managing expected growth.

The first of these is perhaps the least interesting for this audience, as it raises issues around the relationships between Zones and academic units in a context in which each unit has its own local practices, developed independently over its 
history; issues of governance and policy; questions of funding, especially in relation to the major funding bodies such as the Ontario government; and the intersections of faculty - both as educators and as researchers - with the Zones.

From the point of view of this paper, it is probably this last aspect that is most critical. As we move forward, it is my belief that the Zones - including the DFZ must develop in such a way as to avoid two potential problems, either of which could have a serious negative effect on their success. On the one hand, the Zones must resist the desire to bring them into conformance with institutional norms, policies and procedures that exist elsewhere in the University. The Zones present at least the potential for a radical re-thinking of post-secondary education, and this re-thinking will need the flexibility to develop its own means of operating. On the other hand, the Zones must avoid becoming so differentiated from the rest of the University that they become essentially another silo, closed off from the remainder of the institution. The Zones will have to find a way to remain "barnyards" - spaces for play, in which the expertise of the disciplinary silos can begin to be brought together in productive collaboration.

In order to find a balance between these two extremes, a third way of thinking about the Zones will need to be developed that considers the Zones as independent entities but with soft edges - a bit like receptor sites - able to take in ideas, projects and people from other units without having to worry too much about identification or territory. The first two years of the DFZ and the first five years of Zones at Ryerson have already taught us that this idea - operating without regards to territory - is itself a radical idea in the context of a University; for example, it was not an easy sell in my department to allow DFZ members access to our fabrication facilities. As we move forward, we will need to continue to break down institutional and territorial boundaries.

From that perspective, probably the most important development for the DFZ in particular will be to allow greater access to the Zone for non-program students. For the pilot period, membership in the DFZ has been limited to Ryerson program students; however, in the longer term we expect membership to be opened to students, recent graduates, mid-career professionals, researchers - and anyone else with an interest in this activity. Freeing up the membership requirement in this way will require some additional work. For example, we produced, last year, a proposal for a Professional Masters Diploma in Digital Fabrication, intended to be linked to the DFZ, which will allow mid-career professionals to participate in the Zone. In the next year I expect to start work on the development of a Community Design Centre - a professional practice in architecture, working out of the Zone on design work for community groups, operated on a non-profit basis and with Zone members as the primary workforce. As you can imagine, the details involved in bringing these initiatives to fruition are not trivial.

Finally, it is our hope that the DFZ will continue to expand both in terms of numbers and in terms of scope. With an expanded scale, of course, will come expanded need for resources - space, equipment and people. As we have seen, the current operations of the DFZ have been developed in an ad-hoc and opportunistic manner. However, the University is now in the planning stages for the construction of new space for the Zones, including a nationally significant digital fabrication facility, scheduled to open in 2018. 


\section{CONCLUSION}

The Design Fabrication Zone at Ryerson University has been an exciting and successful organization in its first sixteen months of operation. However, we are still in the early days. The potential for the DFZ to impact architectural education at Ryerson and beyond is huge, and its real impact will only grow as the Zone matures and expands.

\section{BIBLIOGRAPHIC REFERENCES}

Faculty of Engineering and Architectural Science [FEAS], Ryerson University, 2014, Synergy [online]. Toronto: Faculty of Engineering and Architectural Science, Ryerson University. [Accessed 30 March 2015]. Available from: http://www.ryerson.ca/content/dam/feas/research/synergy2014.pdf

Ontario Association of Architects, 2014, Becoming an Architect: Sustaining Our Future. Unpublished

Ripley, Colin, 2012, Ceci Tuera Cela. In: Change: Architecture Education Practices. Washington, D.C. : ACSA Press. 2012. p. 14

Robinson, Dickon, Jamieson, Claire, Worthington, John and Cole, Caroline, 2010, The Future For Architects? [online]. London: Royal Institute of British Architects. [Accessed 30 March 2015]. Available from: http://www.buildingfutures.org.uk/projects/building-futures/the-future-forarchitects/the-future-for-architects-report/

Ryerson University, 2014, Zone Learning. [online]. 2014. [Accessed March 30, 2015]. Available from: www.ryerson.ca/zonelearning

UBI Index, 2015, Top Business Incubation Rankings 2014. [online]. 2015. [Accessed February 15, 2015]. Available from: http://ubiindex.com/ranking/ranking-2014/ 